\title{
A measurable treatment plan: Using the Children's Global Assessment and the Problem Severity scales as outcomes of clinical treatment
}

\author{
Jason Novick*1, David Cawthorpe ${ }^{2,3}$, Alan McLuckie ${ }^{4}$ \\ ${ }^{1}$ University of Calgary, Calgary, Alberta, Canada \\ ${ }^{2}$ Departments of Psychiatry \& Community Health Sciences, University of Calgary, Calgary, Alberta, Canada \\ ${ }^{3}$ Child and Adolescent Mental Health and Psychiatry Program, Alberta Health Services, Calgary, Alberta, Canada \\ ${ }^{4}$ Faculty of Social Work, University of Calgary, Calgary, Alberta, Canada
}

Received: October 15,2016

Accepted: November 29, 2016 Online Published: December 6, 2016

DOI: $10.5430 /$ jha.v6n1p9

URL: http://dx.doi.org/10.5430/jha.v6n1p9

\begin{abstract}
Objective: To investigate the psychometric properties of the Children's Global Assessment Scale (CGAS) and the strength/concern (Problem Severity [PS]/Symptom) scale, collectively known as the measurable treatment plan (MTP).

Methods: We draw on a sample of consecutive patients $(n=25,563)$ enrolled for care between 2002 and 2016 in the Child \& Adolescent Addictions and Mental Health Psychiatry Program of the Alberta Health Services, Calgary Health Zone. CGAS reliability was estimated using the Pearson Product-Moment correlation for repeated measures between referral and admission. For the internal consistency of paired referral and admission CGAS scores, $\alpha=0.82$. We estimated the predictive validity of the CGAS and the strength/concern scale using analyses of variance with the demographic variables age and sex, and additionally the system variables service level, treatment completion and provisional diagnosis as covariates of analysis in a final reduced model or as independent variables where warranted.

Results: We discovered that there is a high level of agreement between paired referral and admission CGAS scores. We also discerned functional improvement and symptom reduction on discharge which was attributable to the effect of treatment alone. Importantly, patients who were categorized at the urgent/emergent service level of care at admission, exhibited more severe provisional diagnoses, and/or discontinued treatment attained lower function and PS ratings at discharge.

Conclusions: Overall, the current study supports the empirical applicability of using the MTP to clinically profile on admission those at risk of poor treatment outcomes and to undertake necessary modifications to the treatment process.
\end{abstract}

Key Words: Children's mental health services, Clinical treatment, Children's Global Assessment Scale, Problem Severity, Measurable treatment plan

\section{INTRODUCTION}

Assessing child and youth mental health (CYMH) services is essential for mental health providers to gauge the clinical effectiveness of clinical interventions. ${ }^{[1,2]}$ Program evalu- ation is imperative for the improvement of social service programs and the dissemination of evidence about program effectiveness to stakeholders. ${ }^{[3]}$ Understanding the nature of the population serviced (i.e., patient characteristics) through

\footnotetext{
*Correspondence: Jason Novick; Email: jnovick@mtroyal.ca; Address: Owerko Centre, Child Development Centre, Alberta Children’s Hospital
} Research Institute, Calgary, Alberta, Canada. 
program evaluation is also an essential element in the effective implementation of evidence-based medicine. ${ }^{[4]}$ Investigating symptom reduction across treatment time points is a cornerstone of clinical evaluation, ${ }^{[5-7]}$ for example, the impact of cognitive behavioural group therapy upon reducing symptoms of posttraumatic stress, depression, and anxiety among schoolchildren and their caregivers. ${ }^{[8]}$

\section{Literature review}

Research has emphasized the importance of early intervention, ${ }^{[9]}$ high-quality therapeutic relationships, ${ }^{[10]}$ and undertaking an adaptive treatment disposition ${ }^{[11]}$ in order to enhance therapeutic response among patients. Through assessing the overall symptom reduction of patients, CYMH programming ideally enhances academic performance, ${ }^{[12]}$ alleviates the demands placed on family caregivers, ${ }^{[6]}$ minimizes the possibility of relapse, ${ }^{[13]}$ and improves the delivery of mental health services as a whole. ${ }^{[14]}$

Mental health screening instruments provide clinically useful information to help inform patient assessments as well as provide a basis for evaluation across time or to a normative sample. ${ }^{[15]}$ One such screening instrument is the Children's Global Assessment Scale (CGAS), ${ }^{[16]}$ a measure of psychosocial functioning during the preceding month. Studies have demonstrated the excellent validity and reliability of this scale within hospital and community settings, ${ }^{[17-19]}$ along with its feasible integration into clinical practice. ${ }^{[20]}$ Overall, the clinical application of the CGAS has been advantageous for measuring function change in patients ${ }^{[21]}$ and evaluating the efficacy of CYMH treatment. ${ }^{[22]}$

In this paper, we report the in situ psychometric properties of the CGAS using a repeated measures design between referral and admission. We also report on the validity of the CGAS analyzed in relation to demographic and system variables (service level, provisional diagnosis and discharge disposition) as well as in relation to a strength/concern (Problem Severity [PS]/Symptom) scale. Our main objective is to examine the efficacy of these two scales (collectively known as the measurable treatment plan [MTP]) as predictive outcome measures for patients enrolled within CYMH services. We hypothesize a high level of agreement between paired referral and admission CGAS scores, along with functional improvement and symptom reduction at discharge as a result of treatment. We also hypothesize that patients who were categorized at the urgent/emergent service level of care at admission, exhibited more severe provisional diagnoses, and/or discontinued treatment attained lower function and PS ratings at discharge.

\section{Methodology}

\subsection{Instruments}

The $\mathrm{CGAS}^{[16]}$ is a measure of functioning within the last month for children under the age of 18 that is independent of specific mental health diagnosis. This measure was adapted from the adult Global Assessment Scale, ${ }^{[23]}$ popularized through inclusion in the multiaxial assessment procedure of the Diagnostic and Statistical Manual of Mental Disorders. ${ }^{[24]}$ The CGAS is a clinician completed numeric scale from 1 , lowest functioning to 100 , highest functioning. Behavioural descriptors of functioning levels are provided in increments of 10 with a child rated 1-10 requiring constant supervision, 41-50 denoting moderate functioning and 91100 indicating superior functioning in all areas. In addition to employing the CGAS, we also used a strength-concern rating scale (PS) based on the Goal Attainment Scaling model of community child and family mental health service evaluation. ${ }^{[25]}$ Together these two measures constitute the cornerstones of our regional evaluation model comprised of the expectation of functional improvement and symptom reduction. Measurement of function (CGAS) and PS (Strength and Concern) ratings on admission and discharge permitted the measurement of treatment effect on adaptive function and problems (e.g., symptom reduction), as well as measurement of the modifying effects of strengths (resilience). However, as our system of care is a disease-focused enterprise, only 59 strengths were measured since 2002, likely due to staff time constraints and mandate. Together with a goal attainment scale (GA: not reported), this approach to measurement has been regionally termed MTP, and is akin to the function and problem domains of goal attainment scaling that were developed for measuring the effect of children's mental health services. ${ }^{[25]}$

\subsection{Data collection procedures}

CGAS scores were collected at the time of referral by the regional access and intake staff, as item 5 from the Western Canada Waiting List Children's Mental Health Priority Criteria Score (WCWL-CMH-PCS) form, ${ }^{[26]}$ and again on admission and discharge. PS scores were collected on admission and discharge.

\subsection{Subjects}

The sample was drawn from consecutive patients enrolled for care between 2002 and 2016 in the Child \& Adolescent Addictions and Mental Health Psychiatry Program (CAAMHP) of the Alberta Health Services, Calgary Health Zone. Of 98,571 consecutive referrals, 85,757 (51.4\% female; Chi Square $p<.0001)$ were accepted for some level of service provision (assessment, consultation, treatment) with CAAMHP. However, the final sample was further reduced 
to 56,422 (53\% females) when patients without discharge CGAS scores were excluded where a functional assessment was not practical or feasible (e.g., assessment, consultation, early discharge, etc.). Males (mean age 11.89 years; standard deviation 3.90 years) were younger than females (mean age 13.57; standard deviation 3.26 years). Further reduction in the sample size to a smaller number $(\mathrm{n}=25,563)$ ( $48.61 \%$ females) resulted from using provisional diagnosis and the CGAS on referral, which was derived from item 5 of the WCWL-CMH-PCS form, ${ }^{[26]}$ a form only completed on new referrals and enrollments from the community and not usually collected on transfers or direct readmissions. At the 0.05 level, Ordinary Least Squares regression estimates reveal that sex (female $=1)(\mathrm{B}=1.48)$ and service level (urgent/emergent $=1)(\mathrm{B}=2.63)$ have statistically significant effects on age. Among this sample, 18,758 $(73.38 \%)$ were categorized at the scheduled urgency level and 6,805 (26.6\%) at the urgent/emergent urgency levels for access to psychiatric care. Provisional diagnoses associated with the WCWL-CMH-PCS form were also collected on 25,563 enrolled patients (adjustment disorder $27.43 \%$, attention deficit hyperactivity disorder (ADHD) $13.92 \%$, conduct disorder/oppositional defiant disorder (CD/ODD) $43.30 \%$, pervasive developmental disorder (PDD)/autism 1.67\%, anxiety/depression $8.55 \%$, substance use disorder $2.91 \%$, psychosis $2.22 \%$ ).

Additionally, the PS component of the MTP was not implemented until 2008 and as a result, the ANOVA models were based on a smaller, yet, representative sample ( $n=4,915$ for CGAS and $n=4,883$ for PS, respectively).

\section{Analysis}

Our analysis examined the reliability of the CGAS collected on referral and admission. CGAS clinical effect was examined by comparing scores on admission and discharge. For the internal consistency of paired referral and admission CGAS scores, $\alpha=0.82$. CGAS reliability was estimated using the Pearson Product-Moment correlation (Pearson's $r$ ) for paired referral and admission CGAS scores. We estimated the predictive validity of the CGAS and the strength/concern rating using analysis of variance with the demographic variables age and sex, and additionally the system variables service level (e.g., scheduled vs. emergent), treatment completion and provisional diagnosis as covariates of analysis in a final reduced model or as independent variables where warranted. For inclusion in ANOVA, provisional diagnoses were ranked from least to most severe by admission CGAS in order to form a simple ordinal variable. For the purpose of examining convergent, predictive and criterion-related validity, admission and discharge PS were the independent variables in the model with discharge CGAS as the depenPublished by Sciedu Press dent variable, whereas admission and discharge CGAS were the independent variables in the model with discharge PS as the dependent variable, along with service level, treatment completion, diagnosis, sex, and age.

\section{Results}

\subsection{Reliability of function scores on referral and admis- sion}

For the Pearson's $r$ between the CGAS scores at the time of referral, $r=0.61$ and is statistically significant $(p<.05)$. Additionally, there are statistically significant modifying effects of age and sex ( $r=0.53$ for males and $r=0.55$ for females under 12 years of age, and $r=0.63$ for males and $r=0.64$ for females over the age of 11 years).

\subsection{Validity of function and PS scores on admission and discharge}

Table 1 presents the mean descriptive statistics for admission and discharge CGAS and PS scores by provisional diagnosis and treatment completion status. On average discharge scores for both variables were lower on admission compared to discharge. Table 1 shows that the highest rated treatment outcomes were realized by patients provisionally diagnosed with adjustment disorder. The least satisfactory treatment outcomes were realized by patients with psychosis and substance use disorder. However, the greatest functional improvement was observed in patients with psychosis, whereas those having ADHD and PDD diagnoses experienced the greatest change in PS.

Table 1 presents the differences between admission and discharge CGAS and PS scores by treatment completion status. Among participants who did not complete treatment, we see that the average CGAS score at discharge was lower compared to completers. Table 1 also presents the differences between admission and discharge CGAS and PS scores by service level. Among those admitted to the urgent/emergent, the average CGAS and PS scores at discharge were lower compared to those admitted to scheduled services.

Table 2 presents two analyses of variance with the respective discharge CGAS and PS scores as dependent variables modeled with the independent variables age and sex, the service level, treatment completion status, provisional diagnosis and the respective admission and discharge PS or CGAS ratings. All variables in the first analysis were significant predictors of the discharge CGAS score, with the exception of age. Similarly, all variables in the second analysis were significant predictors of the discharge PS score, with the exception of sex. Overall, these models explain $51 \%$ of the variance in discharge CGAS scores and $42 \%$ of the variance in discharge PS scores, as predicted by admission and discharge PS and CGAS respectively. 
Table 1. Descriptive statistics by independent variables

\begin{tabular}{|c|c|c|c|c|c|}
\hline & & Admission CGAS & Discharge CGAS & PS Admission & PS Discharge \\
\hline \multirow{5}{*}{ Adjustment Disorder } & Obs & 5,140 & 4,996 & 1,339 & 1,260 \\
\hline & Mean & 52.59 & 56.71 & 33.97 & 57.91 \\
\hline & Std. Err. & 0.16 & 0.17 & 0.47 & 0.69 \\
\hline & L95\%CI & 52.27 & 56.38 & 33.04 & 56.56 \\
\hline & U95\%CI & 52.9 & 57.05 & 34.89 & 59.26 \\
\hline \multirow{5}{*}{ ADHD } & Obs & 2,425 & 2,327 & 712 & 701 \\
\hline & Mean & 49.95 & 55.15 & 26.84 & 64.06 \\
\hline & Std. Err. & 0.22 & 0.23 & 0.53 & 0.87 \\
\hline & $\mathrm{L} 95 \% \mathrm{CI}$ & 49.51 & 54.69 & 25.8 & 62.35 \\
\hline & $\mathrm{U} 95 \% \mathrm{CI}$ & 50.38 & 55.61 & 27.88 & 65.77 \\
\hline \multirow{5}{*}{$\mathrm{CD} / \mathrm{ODD}$} & Obs & 7,744 & 7,392 & 2,454 & 2,407 \\
\hline & Mean & 48.81 & 54.51 & 30.48 & 58.18 \\
\hline & Std. Err. & 0.13 & 0.14 & 0.31 & 0.52 \\
\hline & L95\%CI & 48.56 & 54.23 & 29.87 & 57.15 \\
\hline & U95\%CI & 49.05 & 54.79 & 31.08 & 59.21 \\
\hline \multirow{5}{*}{ PDD/Autism } & Obs & 293 & 292 & 72 & 70 \\
\hline & Mean & 41.62 & 44.79 & 21.93 & 54.2 \\
\hline & Std. Err. & 0.87 & 0.85 & 1.53 & 2.72 \\
\hline & L95\%CI & 39.9 & 43.12 & 18.88 & 48.77 \\
\hline & $\mathrm{U} 95 \% \mathrm{CI}$ & 43.34 & 46.47 & 24.98 & 59.63 \\
\hline \multirow{5}{*}{ Anxiety/Depression } & Obs & 1,518 & 1,495 & 301 & 295 \\
\hline & Mean & 46.88 & 50.24 & 23.47 & 46.97 \\
\hline & Std. Err. & 0.26 & 0.28 & 0.71 & 1.16 \\
\hline & L95\%CI & 46.37 & 49.69 & 22.07 & 44.69 \\
\hline & U95\%CI & 47.39 & 50.8 & 24.87 & 49.26 \\
\hline \multirow{5}{*}{$\begin{array}{l}\text { Substance Use } \\
\text { Disorder }\end{array}$} & Obs & 583 & 570 & 113 & 112 \\
\hline & Mean & 45.21 & 48.28 & 24.59 & 43.55 \\
\hline & Std. Err. & 0.44 & 0.44 & 1.28 & 1.77 \\
\hline & L95\%CI & 44.34 & 47.42 & 22.07 & 40.04 \\
\hline & $\mathrm{U} 95 \% \mathrm{CI}$ & 46.08 & 49.14 & 27.12 & 47.06 \\
\hline \multirow{5}{*}{ Psychosis } & Obs & 448 & 447 & 159 & 158 \\
\hline & Mean & 37.25 & 44.26 & 21.04 & 45.92 \\
\hline & Std. Err. & 0.59 & 0.61 & 0.97 & 1.83 \\
\hline & $\mathrm{L} 95 \% \mathrm{CI}$ & 36.1 & 43.05 & 19.13 & 42.3 \\
\hline & U95\%CI & 38.41 & 45.47 & 22.96 & 49.54 \\
\hline \multirow{5}{*}{ Incomplete Treatment } & Obs & 26,947 & 25,369 & 8,916 & 8,520 \\
\hline & Mean & 47.28 & 51.16 & 29.18 & 48.07 \\
\hline & Std. Err. & 0.07 & 0.07 & 0.15 & 0.21 \\
\hline & L95\%CI & 47.14 & 51.02 & 28.88 & 47.66 \\
\hline & $\mathrm{U} 95 \% \mathrm{CI}$ & 47.41 & 51.3 & 29.49 & 48.48 \\
\hline \multirow{5}{*}{ Treatment Completed } & Obs & 21,488 & 21,488 & 10,067 & 10,067 \\
\hline & Mean & 49.31 & 56.59 & 33.61 & 67.47 \\
\hline & Std. Err. & 0.08 & 0.09 & 0.15 & 0.29 \\
\hline & L95\%CI & 49.15 & 56.41 & 33.3 & 66.91 \\
\hline & $\mathrm{U} 95 \% \mathrm{CI}$ & 49.47 & 56.77 & 33.91 & 68.03 \\
\hline \multirow{5}{*}{$\begin{array}{l}\text { Scheduled Service } \\
\text { Level }\end{array}$} & Obs & 33,390 & 31,988 & 14,098 & 13,612 \\
\hline & Mean & 50.95 & 56.99 & 34.03 & 63.69 \\
\hline & Std.Err. & 0.06 & 0.07 & 0.13 & 0.24 \\
\hline & L95\%CI & 50.83 & 56.85 & 33.77 & 63.22 \\
\hline & $\mathrm{U} 95 \% \mathrm{CI}$ & 51.07 & 57.13 & 34.28 & 64.16 \\
\hline \multirow{5}{*}{$\begin{array}{l}\text { Urgent/Emergent } \\
\text { Service Level }\end{array}$} & Obs & 17,793 & 18,157 & 5,030 & 5,018 \\
\hline & Mean & 43.84 & 48.09 & 24.64 & 44.68 \\
\hline & Std.Err. & 0.09 & 0.08 & 0.19 & 0.23 \\
\hline & L95\%CI & 43.67 & 47.93 & 24.27 & 44.23 \\
\hline & U95\%CI & 44.01 & 48.24 & 25 & 45.13 \\
\hline
\end{tabular}

Note. CGAS: Children's Global Assessment Scale; PS: Problem Severity; ADHD: Attention deficit hyperactivity disorder; CD/ODD: Conduct disorder/ oppositional defiant disorder; PDD: Pervasive development disorder 
Table 2. Outcome CGAS and PS ANOVA results

\begin{tabular}{|c|c|c|c|c|c|}
\hline \multicolumn{6}{|c|}{ Discharge CGAS } \\
\hline Number of obs $=4,915$ & Root MSE $=9.11$ & & Adj Rsquared $=0.50$ & Rsquare & \\
\hline Source & Partial SS & $d f$ & $M S$ & $\boldsymbol{F}$ & Prob $>F$ \\
\hline Model & 417,678 & 166 & $2,516.13$ & 30.35 & 0.00001 \\
\hline Sex & 690.47 & 1 & 690.47 & 8.33 & 0.0039 \\
\hline Age & $2,061.3$ & 16 & 128.83 & 1.55 & 0.0728 \\
\hline Service Level & $31,652.7$ & 1 & $3,1652.7$ & 381.81 & 0.00001 \\
\hline Completed Treatment & $2,020.9$ & 1 & $2,020.9$ & 24.38 & 0.00001 \\
\hline Diagnosis & $16,522.3$ & 6 & $2,753.72$ & 33.22 & 0.00001 \\
\hline Admission Problem Severity & 13,866 & 52 & 266.65 & 3.22 & 0.00001 \\
\hline Discharge Problem Severity & 105,331 & 89 & $1,183.5$ & 14.28 & 0.00001 \\
\hline Residual & 393,616 & 4,748 & 82.9 & & \\
\hline Total & 811,295 & 4,914 & 165.1 & & \\
\hline \multicolumn{6}{|c|}{ Discharge PS } \\
\hline Number of obs $=4,883$ & Root $\mathrm{MSE}=18.95$ & & Adj Rsquared = 0.41 & Rsquare & \\
\hline Source & Partial SS & $d f$ & $M S$ & $\boldsymbol{F}$ & Prob $>F$ \\
\hline Model & $1,233,380$ & 42 & $29,366.2$ & 81.77 & 0.00001 \\
\hline Sex & 249.85 & 1 & 249.85 & 0.7 & 0.4043 \\
\hline Age & $13,924.1$ & 16 & 870.26 & 2.42 & 0.0012 \\
\hline Service Level & $2,534.57$ & 1 & $2,534.57$ & 7.06 & 0.0079 \\
\hline Completed Treatment & $69,089.7$ & 1 & $69,089.7$ & 192.37 & 0.00001 \\
\hline Diagnosis & $28,286.5$ & 6 & $4,714.41$ & 13.13 & 0.00001 \\
\hline Admission CGAS & $40,310.9$ & 8 & $5,038.87$ & 14.03 & 0.00001 \\
\hline Discharge CGAS & 516,645 & 9 & $57,405.1$ & 159.84 & 0.00001 \\
\hline Residual & $1,738,294$ & 4,840 & 359.15 & & \\
\hline Total & $2,971,673$ & 4,882 & 608.7 & & \\
\hline
\end{tabular}

Note. CGAS: Children's Global Assessment Scale; PS: Problem Severity

\section{Discussion}

Notwithstanding age and sex effects, the referral and admission CGAS scores had acceptable levels of Pearson productmoment correlation indicating reliability. ${ }^{[27]}$ The correlation coefficient was a combination of test-retest and interrater reliability, as different staff members completed the CGAS scores on referral and admission. In addition to reliability, measuring CGAS twice before admission established a patient's trajectory and provided a basis for estimating the validity of the CGAS as a measure of treatment effect when examined at discharge.

Improvement of client function and PS at discharge was attributable to the effect of treatment based on the change in slope between admission and discharge as compared to its stability between referral and admission. Measuring trajectory controlled for the effect of time in that each patient's CGAS score served as their own waitlist control compared to discharge. While past studies have examined the use of the CGAS with varying results, ${ }^{[28-30]}$ the current study controlled for the effect of time in measuring trajectory, as a result indicated that the CGAS reliably measured function at service standard encounter points and validly measured treatment effect at discharge.
The change in function (CGAS) between admission and discharge paralleled the change in the independent measure of PS. Additional support for the validity of the CGAS and PS as indices of function and problem change comes from the theoretically meaningful relationship with treatment completion status and provisional diagnosis. One would expect, as observed, patients who discontinued treatment received lower function and PS rating at discharge compared to those who completed treatment. Similarly, patients diagnosed with what are considered more severe diagnoses (psychosis, autism, or substance use disorder) had the lowest admission function and PS scores. While all patients were reported to demonstrate improved functioning and reduced symptomatology regardless of their provisional diagnosis, our results are consistent with previous research highlighting the poor prognoses of patients experiencing these particular mental illnesses, ${ }^{[31-33]}$ in addition to those who do not complete treatment.

\section{Conclusions}

Overall, the current study demonstrates the sound psychometric properties of the MTP as a measure of client improvement. While providing an index of validity in terms of diagnosis and treatment completion, those who do not 
improve as much are of paramount concern when already enrolled in care. Together with the WCWL-CMH-PCS form, there is the opportunity to use the MTP to clinically profile on admission those at risk of poor treatment outcomes once they are enrolled. The present study forms a cornerstone of this planned work. Additionally, and consistent with evidence based medicine, ${ }^{[34]}$ the present results encourage development of a modular treatment process that recognizes a differential treatment response to account for patient characteristics and clinical state on admission.

The MTP model of outcome evaluation stemmed from goal attainment scaling. It is a boon to the crisis currently faced in evidence based medicine. ${ }^{[35]}$ It has also been generalized

\section{REFERENCES}

[1] Ruble L, McGrew JH, Toland MD. Goal attainment scaling as an outcome measure in randomized controlled trials of psychosocial interventions in autism. J Autism Dev Disord. 2012; 42(9): 19741983. PMid: 22271197. https://doi.org/10.1007/s10803-0 12-1446-7

[2] Grinnell R, Gabor P, Unrau Y. Program evaluation for social workers: Foundations of evidence-based programs. New York, NY: Oxford University Press; 2011.

[3] Zhang G, Zeller N, Griffith R, et al. Using the context, input, process, and product evaluation model (CIPP) as a comprehensive framework to guide the planning, implementation, and assessment of servicelearning programs. J High Educ Outreach Engagem. 2011; 15(4): 57-84.

[4] Sackett DL, Rosenberg WM, Gray JA, et al. Evidence based medicine: what it is and what it isn't. Clin Orthop Relat Res. 1996; 312(7023): 71-72.

[5] Vu M, Law AV. Goal-attainment scaling: a review and applications to pharmacy practice. Res Social Adm Pharm. 2012; 8(2): 102-121. https://doi.org/10.1016/j.sapharm.2011.01.003

[6] Hoagwood K, Jensen P, Petti T, et al. Outcomes of mental health care for children and adolescents: a comprehensive conceptual model. J Am Acad Child Adolesc Psychiatry. 1996; 35(8): 1055-1063 https://doi.org/10.1097/00004583-199608000-00017

[7] Durbin J, Prendergast P, Dewa CS, et al. Mental health program monitoring: towards simplifying a complex task. Psychiatr Rehabil J. 2003; 26(3): 249-261. PMid: 12653447. https://doi.org/10.2 $975 / 26.2003 .249 .261$

[8] Langley AK, Gonzalez A, Sugar CA, et al. Bounce back: effectiveness of an elementary school-based intervention for multicultural children exposed to traumatic events. J Consult Clin Psychol. 2015; 83(5): 853-865. https://doi.org/10.1037/ccp0000051

[9] Marshall M, Rathbone J. Early intervention for psychosis. Schizophr Bull. 2011; 37(6): 1111-1114. https://doi.org/10.1093/schb $\mathrm{ul} / \mathrm{sbr} 110$

[10] Blatt SJ, Zuroff DC. Empirical evaluation of the assumptions in identifying evidence based treatments in mental health. Clin Psychol Rev 2005; 25(4): 459-486. https ://doi.org/10.1016/j.cpr. 2005 .03 .001 beyond children's mental health intervention evaluation and has been published as an application known as the Treatment Response and Client Tracking (TRACT) in service of documenting the assessment and treatment for any disease, disorder, or problem and published in the WHO compendium of emerging technologies. ${ }^{[36]}$ The ability to measure complex clinical outcomes for any treatment effectively and efficiently using the MTP concept, as generalized in TRACT, widens the range of application to all health service interventions and improves the ability to provide evidence of practice effect in the field.

\section{CONFLicts OF InTEREST Disclosure}

The authors have no potential conflicts of interest to report.
[11] Almirall D, Chronis-Tuscano A. Adaptive interventions in child and adolescent mental health. J Clin Child Adolesc Psychol. 2016; 45(4): 383-395. https : //doi.org/10.1080/15374416.2016.115255 5

[12] Masten AS, Roisman GI, Long JD, et al. Developmental cascades: linking academic achievement and externalizing and internalizing symptoms over 20 years. Dev Psychol. 2005; 41(5): 733-746. PMid: 16173871. https://doi.org/10.1037/0012-1649.41.5.733

[13] Asbahr FR, Castillo AR, Ito LM, et al. Group cognitive-behavioral therapy versus sertraline for the treatment of children and adolescents with obsessive-compulsive disorder. J Am Acad Child Adolesc Psychiatry. 2005; 44(11): 1128-1136. PMid: 16239861. https://doi.org/10.1097/01.chi.0000177324.40005.6f

[14] Kataoka SH, Stein BD, Jaycox LH, et al. A school-based mental health program for traumatized Latino immigrant children. J Am Acad Child Adolesc Psychiatry. 2003; 42(3): 311-318.

[15] Lundh A, Forsman M, Serlachius E, et al. Psychosocial functioning in adolescent patients assessed with Children's Global Assessment Scale (CGAS) predicts negative outcomes from age 18: a cohort study. Psychiatry Res. 2016; 242: 295-301.

[16] Shaffer D, Gould MS, Brasic J, et al. A Children's Global Assessment Scale (CGAS). Arch Gen Psychiatry. 1983; 40(11): 1228-31. https : //doi.org/10.1001/archpsyc.1983.01790100074010

[17] Edbrooke-Childs J, Jacob J, Argent R, et al. The relationship between child- and parent-reported shared decision making and child-, parent-, and clinician-reported treatment outcome in routinely collected child mental health services data. Clin Child Psychol Psychiatry. 2016; 21(2): 324-338. PMid: 26104790. https://doi.org/10.1177/ 1359104515591226

[18] Dyrborg J, Larsen FW, Nielsen S, et al. The Children's Global Assessment Scale (CGAS) and Global Assessment of Psychosocial Disability (GAPD) in clinical practice - substance and reliability as judged by intraclass correlations. Eur Child Adolesc Psychiatry. 2000; 9(3): 195-201. PMid: 11095042. https://doi.org/10.1 $007 / \mathrm{s} 007870070043$

[19] Costello EJ, Farmer EM, Angold A, et al. Psychiatric disorders among American Indian and white youth in Appalachia: the Great Smoky Mountains Study. Am J Public Health. 1997; 87(5): 827-832. PMid: 9184514. https://doi.org/10.2105/AJPH.87.5.827 
[20] Nilsen TS, Handegard BH, Eisemann M, et al. Evaluating change in symptomatic and functional level of children and youth with emotional disorders: a naturalistic observation study. Eur Child Adolesc Psychiatry. 2015; 24(10): 1219-31. https ://doi.org/10.1007/ s00787-014-0671-3

[21] Rohde P, Clarke GN, Mace DE, et al. An efficacy/effectiveness study of cognitive-behavioral treatment for adolescents with comorbid major depression and conduct disorder. J Am Acad Child Adolesc Psychiatry. 2004; 43(6): 660-668. https ://doi.org/10.1097/ 01 .chi.0000121067.29744.41

[22] Schorre BE, Vandvik IH. Global assessment of psychosocial functioning in child and adolescent psychiatry: a review of three unidimensional scales (CGAS, GAF, GAPD). Eur Child Adolesc Psychiatry. 2004; 13(5): 273-286. https ://doi .org/10 .1007/s00787-004 -0390-2

[23] Endicott J, Spitzer RL, Fleiss JL, et al. The Global Assessment Scale: A procedure for measuring overall severity of psychiatric disturbance. Arch Gen Psychiatry. 1976; 33(6): 766-71.

[24] American Psychiatric Association. Diagnostic and Statistical Manual of Mental Disorders ( $5^{t h}$ ed.) Arlington, VA: American Psychiatric Association; 2000.

[25] Kiresuk TJ, Sherman RE. Goal attainment scaling: a general method for evaluating comprehensive community mental health programs. Community Ment Health J. 1968; 4(6): 443-453. https://doi .or g/10.1007/BF01530764

[26] Cawthorpe D, Wilkes TC, Rahman A, et al. Priority-setting for children's mental health: clinical usefulness and validity of the priority criteria score. J Can Acad Child Adolesc Psychiatry. 2007; 16(1): 18-26. PMid: 18392175.

[27] Kendall MG. Rank and product-moment correlation. Biometrika. 1949; 36(1): 177-193. PMid: 18132091. https://doi.org/10.1 093/biomet/36.1-2.177

[28] Green B, Shirk S, Hanze D, et al. The Children's Global Assessment Scale in clinical practice: an empirical evaluation. J Am Acad
Child Adolesc Psychiatry. 1994; 33(8): 1158-1164. PMid: 7982866 https : //doi.org/10.1097/00004583-199410000-00011

[29] Hanssen-Bauer K, Aalen OO, Ruud T, et al. Inter-rater reliability of clinician-rated outcome measures in child and adolescent mental health services. Adm Policy Ment.Health. 2007; 34(6): 504-512. PMid: 17846880. https://doi.org/10.1007/s10488-007-0 134-y

[30] Rey JM, Starling J, Wever C, et al. Inter-rater reliability of Global Assessment of Functioning in a clinical setting. J Child Psychol Psychiatry. 1995; 36(5): 787-792. PMid: 7559845. https://doi.or $\mathrm{g} / 10.1111 / \mathrm{j} \cdot 1469-7610.1995 . \mathrm{tb} 01329 \cdot \mathrm{x}$

[31] Bruce SE, Yonkers KA, Otto MW, et al. Influence of psychiatric comorbidity on recovery and recurrence in generalized anxiety disorder, social phobia, and panic disorder: a 12-year prospective study. Am J Psychiatry. 2005; 162(6): 1179-1187. https : //doi.org/10.1176/appi.ajp.162.6.1179

[32] Crawford AM, Manassis K. Familial predictors of treatment outcome in childhood anxiety disorders. J Am Acad Child Adolesc Psychiatry. 2001; 40(10): 1182-1189. https://doi.org/10.1097/000045 83-200110000-00012

[33] McClellan J, McCurry C, Snell J, et al. Early-onset psychotic disorders: course and outcome over a 2-year period. J Am Acad Child Adolesc Psychiatry. 1999; 38(11): 1380-1388.

[34] Haynes RB, Devereaux PJ, Guyatt GH. Physicians' and patients' choices in evidence based practice. BMJ. 2002; 324(7350): 1350. https://doi.org/10.1136/bmj.324.7350.1350

[35] Greenhalgh T, Howick J, Maskrey N. Evidence based medicine: a movement in crisis? BMJ. 2014; 348(3725): 1-7.

[36] Cawthorpe D. Treatment Response Application for Client Tracking, WHO compendium of new and emerging health technologies. Health Data Monitoring. 2011. Available from: http://whqlibdoc. who. int/ 